\title{
A Wide Multiband T-Slotted, Semicircular Microstrip Patch Antenna for WLAN/WiMAX Applications
}

\author{
Madiha Iqtedar ${ }^{1}$, Pratibha Devi Umesh ${ }^{2}$
}

\author{
${ }^{1}$ M Tech Scholar, Department of Electronics and Communication Engineering, TIT \& Science, Bhopal \\ ${ }^{2}$ Associate Professor, Department of Electronics and Communication Engineering, TIT \& Science, Bhopal
}

\begin{abstract}
A multifrequency semicircularmicrostrip antenna is designed and simulated in this paper using HFSS simulation software. The proposed antenna consists of two quarter rings in different radius with one as perfect ground and other as defect ground structure, with an inverted T-shaped slot. The relationship of the resonant frequency with different physical size parameters for the single one-quarter-ring microstrip antenna is also reported. This designed multiresonant antenna proves increase in bandwidth when defect ground is used as compared to normal or conventional ground plane. The simulation show that proposed designed antenna operates at six different frequencies of $1.7,1.93,2.3,3.03,3.57$ and $3.67 \mathrm{GHz}$, respectively for normal ground whereas wide bandwidth of $500 \mathrm{MHz}$ is achieved for $1.9 \mathrm{GHz}$ operating frequency.
\end{abstract}

Keywords- Defect Ground Structure, Multi-band, WLAN /WiMAX, open-ended slot, Rectangular Ground Slot, T Slot etc.

\section{INTRODUCTION}

The Microstrip patch antenna has been investigated sincethe1950s [1]. In recent years, the microstrip antenna played amore and more important role due to its low profile, lightweight, low cost, etc. [2]. With the rapid development of the wireless communication in antenna technology, more and more research focuses on the multiresonant and wideband antennas [3], but complex manufacturing procedures are needed by using stacked, slot patches. Many single-feed, single-layer dualfrequency patch antennas are studied before this proposed research [4]. By loading slots (eliminating some portion from radiation surface) [5], or two different elements [6], a dual-frequency microstrip antenna is obtained[7]. However, these antenna designs only operate at two [7] or four [16] frequencies, and more communication bands are not covered. A novel single-feed, single-layer triplefrequency microstrip antenna is designed in [8]. Further design is optimized by using FR_4 Epoxy $(\varepsilon r=4.4)$ substrate in our proposed design.
People begin to pay more attention to the annular ring microstrip antennas due to their simple structure, compact low profile, simple size reduction, and circular polarization operation[9], [10]. Many analysis about the annular ring microstrip antenna using the cavity model and full-wave analysis are studied [11]-[13]. Based on this research, more than dual- and four-frequency operations on the annular ring patch antenna have been designed and simulated[16]. Combining two semi-ring elements [14], multi-frequency operation can also be obtained. By loading slots, a multi-band frequencytunable annular ring patch antenna [15] is designed and simulated.

A modified multi frequency semicircular microstrip antenna is proposed in this paper. The proposed antenna consists of two quarter rings in different sizes[16], with an inverted T-shaped slot loaded with Perfect ground and Defect ground slots. The relationship of the resonant frequency with different physical size parameters [16] for perfect ground and DGS (Defect Ground Structure) is also considered which is useful to design the proposed multi frequency microstrip patch antenna. The T-shaped slot is mainly used to suppress the higher-order mode [16].

\section{ANTENNA DESIGN}

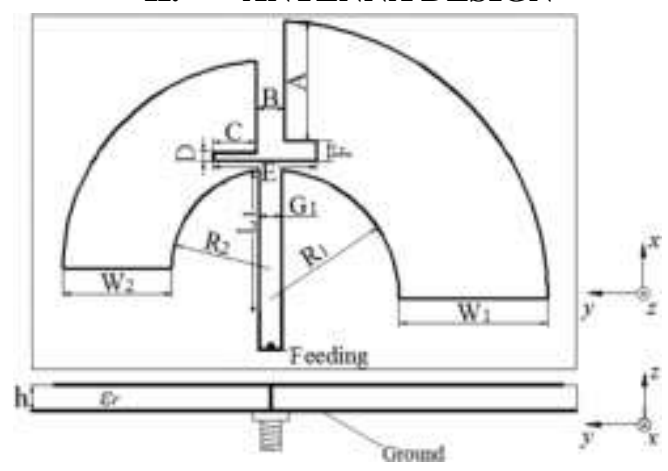

Fig 1(a). Patch Geometry with semicircular. 


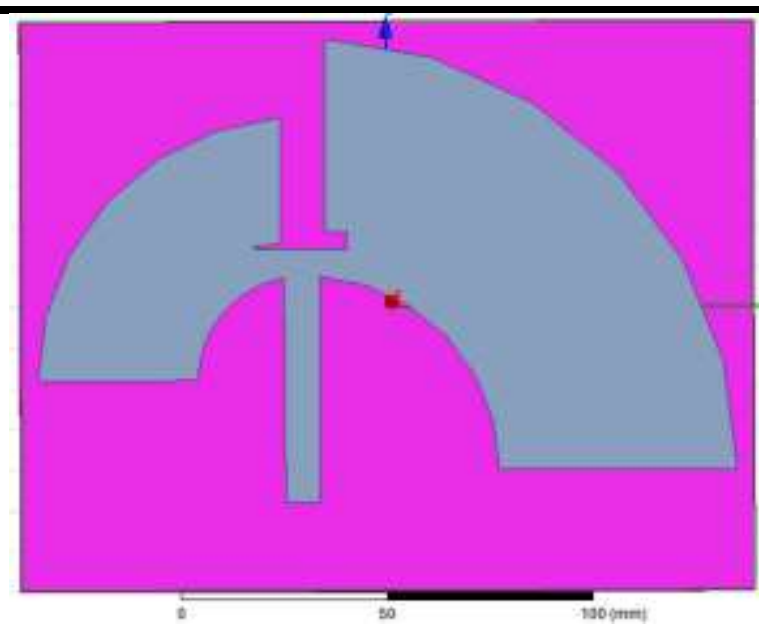

Fig 1(b). Simulated Design Patch Geometry on HFSS

Table 1 . Geometry parameters

\begin{tabular}{|c|c|c|c|c|c|c|}
\hline Symbol & W1 & R1 & W2 & R2 & G1 & L1 \\
\hline $\begin{array}{c}\text { Value } \\
(\mathrm{mm})\end{array}$ & 51 & 47.7 & 39.2 & 25.6 & 5 & 45 \\
\hline Symbol & $\mathrm{A}$ & $\mathrm{B}$ & $\mathrm{C}$ & $\mathrm{D}$ & $\mathrm{E}$ & $\mathrm{F}$ \\
\hline Value $(\mathrm{mm})$ & 39.7 & 11 & 6.5 & 1 & 23 & 4 \\
\hline
\end{tabular}

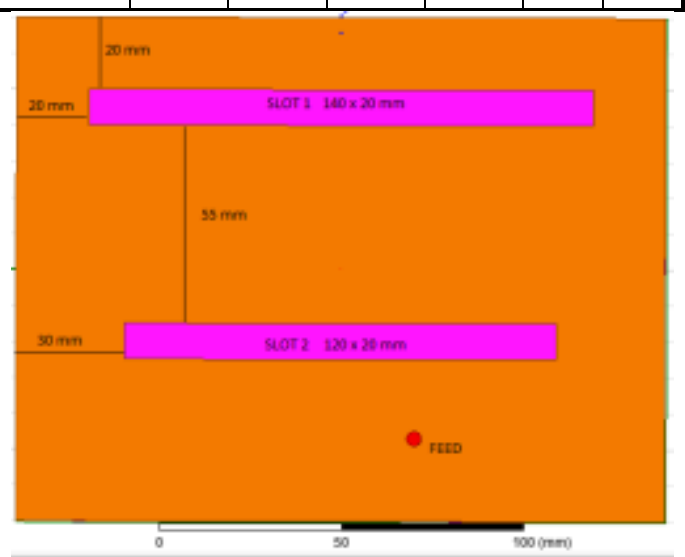

Fig 2. Proposed design for DGS (Defect Ground Structure).

A multifrequency one-semicircular microstrip antenna is shown in Fig. 1, which consists of semicircular in different sizes and an inverted T-shaped slot. The multifrequency semicircular microstrip antenna is designed using FR_4 Epoxy substrate with a permittivity $\varepsilon r=4.4$, a loss tangent of 0.06 , and a thickness (h) of 1.6 $\mathrm{mm}$, respectively. The size of the ground plane is $140 \mathrm{x}$ $180 \mathrm{~mm} 2$. W1, W2, R1 and R2 respectively represent the width and the inner radius as shown in table of the multifrequency semicircular microstrip antenna. A single semicircular annular ring structure has a dominant operating mode, which is the TM11 [17].

The resonant frequencies may be shifted by changing the length and width of the slots (140x $20 \mathrm{~mm}$ and 120x20 $\mathrm{mm}$ ) in ground plane. With addition of DGS, the current distribution gets disturbed and affects the impedance and current flow in the antenna [18]. Two slots are cut with the simulation a test confirms the increase in bandwidth when Defect Ground Structure is implemented, comparative bandwidth is mentioned in table II. But results shows that there is no significant change in the resonating frequency when DGS is applied.

\section{SIMLUATION \& RESULTS}

The The designed antennas are simulated by using commercial Ansoft HFSS software. The probe feed technique is chosen as its direct contact mechanism with the antenna, and mainly of the feed is isolated from the patch, which minimize unwanted radiation. Through simulations, the position and dimensions of the slots are optimized for multiband operation.

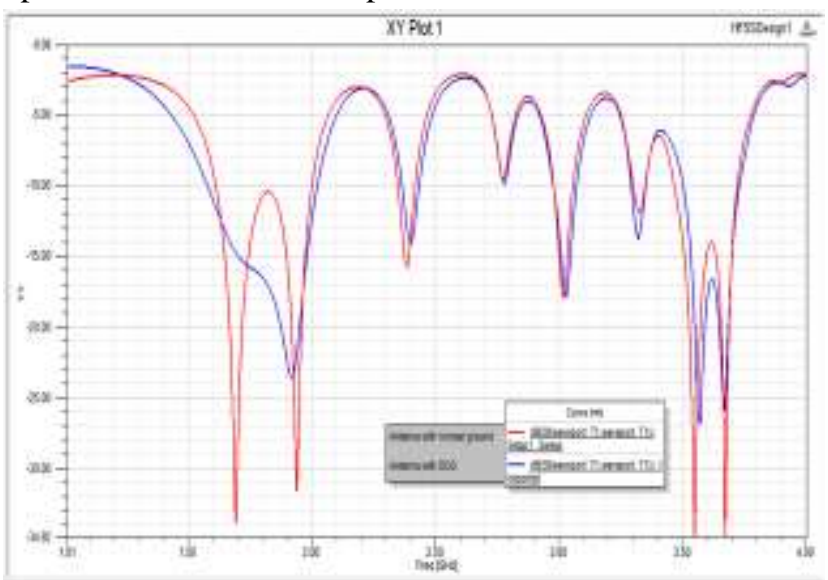

Fig.3: Return loss vs. frequency for proposed design Conventional Ground (Red) and with DGS(Blue).

Table. II: Combined results for both designs

\begin{tabular}{|c|c|c|c|c|}
\hline \multirow{4}{*}{ Geometry } & $\begin{array}{c}\text { Resonating } \\
\text { Freq }(\mathrm{GHz})\end{array}$ & $\begin{array}{c}\mathrm{S} 11 \\
(\mathrm{~dB})\end{array}$ & $\begin{array}{c}\text { Gain } \\
(\mathrm{dBi})\end{array}$ & $\begin{array}{c}\text { Bandwidth } \\
(\mathrm{MHz})\end{array}$ \\
\hline \multirow{4}{*}{$\begin{array}{c}\text { Antenna with } \\
\text { conventional } \\
\text { Ground }\end{array}$} & 1.7 & -33.8 & 2.84 & 200 \\
\cline { 2 - 5 } & 2.4 & -31.6 & 3.01 & 200 \\
\cline { 2 - 5 } & 3.0 & -17.7 & 7.1 & 80 \\
\cline { 2 - 5 } & 3.54 & -33.6 & 3.28 & 250 \\
\hline \multirow{4}{*}{$\begin{array}{c}\text { Antenna with } \\
\text { Defect }\end{array}$} & 2.4 & -34.4 & 7.6 & 70 \\
\cline { 2 - 5 } $\begin{array}{c}\text { Ground } \\
\text { Structure }\end{array}$ & 3.0 & -17.9 & 0.9 & 90 \\
\cline { 2 - 5 } & 3.5 & -26.9 & 4.5 & 50 \\
\cline { 2 - 5 } & 3.6 & -25.9 & 5.6 & 220 \\
\hline
\end{tabular}

Table II provides the results of proposed antenna to the existing probe-feed proposed multiband planar antennas. The presented antenna gives with a slight decay in the measured gain. The variation in the length of the DGS 
slot would acutely affect the impedance matching, whereas less change is seen other than the first and second operation frequency bands. DGS show a vital role in shifting the frequencies and improving bandwidth for the working bands. Miniaturization in the height of the antenna from $3 \mathrm{~mm}$ to $1.6 \mathrm{~mm}$ is obtained by introducing FR_4 substrate and also with a change in the resonant frequencies.

The measured results of the proposed multiband antenna are at $1.7 \mathrm{GHz}, 1.93 \mathrm{GHz}, 2.4 \mathrm{GHz}, 3.0 \mathrm{GHz}, 3.54 \mathrm{GHz}$ and $3.67 \mathrm{GHz}$ respectively, The antenna radiates robustly for six resonant modes in the broadside direction.

$\mathrm{T}$ Slot-loaded multiband patch antenna with defected ground structure is designed and simulated for wireless applications. The simulated resonant frequencies of the modes and respective results of the patch antennas were observed to be in good agreement. The difference between the bandwidths at different frequency bands is undersize. The gain values at the operating frequencies of structure are also measured. Simulated radiation patterns are in good agreement. This study proves the tradeoff between compactness through DGS with gain. The proposed antenna is applicable for wireless communication systems with good bandwidth especially working in L- and S-bands.

\section{CONCLUSION}

To A modified multi frequency semicircular microstrip antenna is proposed in this paper. The proposed antenna consists of two one-quarter rings in different sizes, with an inverted T-shaped slot loaded. The inverted T-shaped slot is mainly used to suppress the higher-order mode. The resonant frequencies of the proposed antenna are evaluated by two one-quarter rings. The relationship of the resonant frequency with different physical size parameters for the single quarter-ring microstrip antenna is also reported, and it contributes to the antenna design. The multi frequency capability is obtained by adjusting the parameters of the proposed structure. The proposed antenna operates at $1.7,1.93,2.3,3.03,3.57$ and 3.67 $\mathrm{GHz}$, respectively. The $\mathrm{S} 11$ is studied, and the radiation patterns at six resonant frequencies are similar. The multi frequency capability will be useful in applications of personal communication systems, such as the indoor base station.

\section{REFERENCES}

[1] C.-A. Balanis, Antenna Theory Analysis and Design. NewYork,NY,USA: Wiley, 1997.

[2] K.-L. Wong, Compact and Broadband Microstrip Antennas. NewYork, NY, USA: Wiley, 2002.

[3] H. Iwasaki and Y. Suzuki, "Dual frequency multilayered circularpatch antenna with self- diplexing function," Electron. Lett., vol. 31,pp. 599601, Apr. 1995.

[4] Q. H. Zhong and Y. X. Li, "Design of a novel dualfrequency microstrippatch antenna forWLAN applications," in Rec. Int. Conf. IEEEAP-S USNC/URSI, Jun. 2004, vol. 1, pp. 277-280.

[5] J.-H. Lu, "Dual-frequency operation of rectangular microstrip antennawith bent-slot loading," in Proc. Asia-Pacific Microw. Conf., Dec.2000, pp. 13431346.

[6] S.-C. Pan and W.-H. Hsu, "Single-feed dualfrequencymicrostripantennawith two patches," in Proc. Antennas Propag. Soc. Int. Symp.,Jul. 1999, vol. 3, pp. 1644-1647.

[7] X. Hu, Y. Li, H.-Z. Tan, and Y. Long, "Novel dualfrequency microstripantenna with narrow half-ring and half-circular patch," IEEEAntennas Wireless Propag. Lett., vol. 12, pp. 3-6, 2013.

[8] X. L. BaoandM. J. Ammann, "Compact concentric annular-ring patchantenna for triple-frequency operation," Electron. Lett., vol. 42, pp.1129-1130, Sep. 2006.

[9] G. J. K. Moernaut and G. A. E. Vandenbosch, "Size reduced meanderline annular ring microstrip antenna," Electron. Lett., vol. 40, pp.1463-1464, Nov. 2004.

[10] H.-M. Chen and K.-L. Wong, "On the circular polarization operationof annular-ring microstrip antennas," IEEE Trans. Antennas Propag.,vol. 47, pt. 8, pp. 1289-1292, Aug. 1999.

[11] S. E. El-Khamy, S. Mem, R. M. El-Awadi, and ElSharrawy, "Simpleanalysis and design of annular ring microstrip antennas," IEE Proc. H,Microw., Antennas Propag., vol. 133, no. 3, pp. 198-202, Jun. 1986.

[12] D. M. Kokotoff, J. T. Aberle, and R. B. Waterhouse, "Rigorous analysisof probe-fed printed annular ring antennas," IEEE Trans. AntennasPropag., vol. 47, no. 2, pp. 384-388, Feb. 1999.

[13] S. M. Ali, W. C. Chew, and J. A. Kong, "Vector Hankel transformanalysis of annular-ring microstrip antenna," IEEE Trans. AntennasPropag., vol. AP-30, no. 4, pp. 637-644, Jul. 1982.

[14] K. Jhamb, L. Li, and K. Rambabu, "Frequency justable microstrip annular ring patch antenna with multi-band characteristics," Microw., Antennas Propag., vol. 5, pp. 1471-1478, Feb. 2011.

[15] Jianbin Zhang, Yuanxin Li, Member, IEEE, Zhixi Liang, Shaoyong Zheng, Member, IEEE, and Yunliang Long, Senior Member, IEEE," Design of a Multifrequency SemicircularMicrostrip Antenna, IEEE Antennas And Wireless Propagation Letters, Vol. 14, 2015. 